\title{
PERFIL DOS EDUCANDOS DO ENSINO MÉDIO DA EJA NUMA ESCOLA PÚBLICA EM MACAPÁ-AP
}

\author{
Antônio Eugênio Furtado Corrêa ${ }^{1}$ \\ Eugénia da Luz Silva Foster ${ }^{2}$ \\ Elivaldo Serrão Custódio ${ }^{3}$
}

\section{RESUMO}

O presente artigo tem como objetivo discorrer sobre o perfil dos educandos do ensino médio na modalidade Educação de Jovens e Adultos (EJA) em uma Escola Pública Estadual em Macapá, estado do Amapá, Brasil, verificando a composição étnica e a ocorrência de educandos classificados como negros, ou como pretos e pardos segundo o Instituto Brasileiro de Geografia e Estatística (IBGE). Tratase de uma pesquisa quali-quantitativa de cunho exploratório que utilizou da pesquisa bibliográfica, da análise documental e da aplicação de um questionário. Os dados foram coletados na secretaria da escola com verificação da ficha de matrícula dos 211 educandos matriculados em 2019 e complementados no questionário respondido por 90 educandos escolhidos aleatoriamente entre os matriculados. Os resultados da pesquisa revelam que as características encontradas nos educandos da escola pesquisada estão presentes e significativas no grupo social ampliado que utiliza essa modalidade como alternativa de ensino para concluir

\footnotetext{
${ }^{1}$ Mestre em Desenvolvimento Regional pela Universidade Federal do Amapá (UNIFAP). ORCID: https://orcid.org/0000-0003-1188-7527.E-mail: eugeniofurtadoc@gmail.com

2 Doutora em Educação (UFF). Pós-doutorado em Educação (UERJ). Professora do Mestrado em Educação da Universidade Federal do Amapá (PPGED/UNIFAP) e do Doutorado em Educação da Região Amazônica (EDUCANORTE). Líder do Grupo de Pesquisa Educação, Interculturalidade e Relações Étnico-Raciais. ORCID: http://orcid.org/0000-0002-0807-0789. E-mail: daluzeugenia6@gmail.com

${ }^{3}$ Doutor em Teologia pela Faculdades EST, em São Leopoldo/RS. Pós-doutor em Educação pela Universidade Federal do Amapá (UNIFAP). Professor no Mestrado em Educação (PPGED/UNIFAP) e Professor coorientador no Doutorado em Educação da Amazônia (EDUCANORTE). Vice-líder do Grupo de Pesquisa Educação, Interculturalidade e Relações Étnico-Raciais (UNIFAP/CNPq). ORCID :http://orcid.org/0000-0002-2947-5347. Email: elivaldo.pa@hotmail.com
} 
o ciclo da educação básica. O levantamento revelou também que as características dos educandos coincidem com as do grupo etnicamente denominado negro, o que leva à conclusão de que a EJA, na forma planejada e implementada, tem uma destinação certa que são os brasileiros e as brasileiras das camadas mais expropriadas da sociedade, o que coincide historicamente com os negros, os indígenas e alguns brancos desprovidos economicamente.

Palavras-chave: EJA. Relações Étnico-Raciais. Amapá.

\section{PERFIL DE ESTUDIANTES DE SECUNDARIA DE EJA EN UNA ESCUELA PÚBLICA EN MACAPÁ-AP}

\section{ABSTRACT}

This article aims to discuss the profile of high school students in the Youth and Adult Education (EJA) modality in a State Public School in Macapá, Amapá state, Brazil, verifying the ethnic composition and the occurrence of students classified as black, or as black and brown according to the Brazilian Institute of Geography and Statistics (IBGE). It is a qualitative and quantitative research of exploratory nature that used the bibliographic research, the documentary analysis and the application of a questionnaire. Data were collected at the school office with verification of the enrollment form of the 211 students enrolled in 2019 and complemented by a questionnaire answered by 90 students randomly selected from the enrolled students. The results of the research reveal that the characteristics found in the students of the researched school are present and significant in the extended social group that uses this modality as a teaching alternative to complete the cycle of basic education. The survey also revealed that the characteristics of the students coincide with those of the ethnically called black group, which leads to the conclusion that the EJA, in its planned and implemented form, has a certain destination that are the Brazilians and the Brazilian from the most expropriated strata of the population. historically coinciding with blacks, indigenous people and some economically deprived whites.

Keywords: EJA. Ethnic-Racial Relations. Amapá. 


\section{REFLEXIONES SOBRE EL APRENDIZAJE PERSONAS JÓVENES Y ADULTOS: DIÁLOGO ENTRE LAS TEORÍAS CRÍTICAS Y LA ANDRAGOGÍA}

\section{RESUMEN}

Este artículo tiene como objetivo discutir el perfil de los estudiantes de secundaria en la modalidad de Educación de Jóvenes y Adultos (EJA) en una Escuela Pública Estatal en Macapá, estado de Amapá, Brasil, verificando la composición étnica y la ocurrencia de estudiantes clasificados como negros, o como negro y marrón según el Instituto Brasileño de Geografía y Estadística (IBGE). Se trata de una investigación exploratoria cualitativa y cuantitativa que utilizó la investigación bibliográfica, el análisis de documentos y la aplicación de un cuestionario. Los datos fueron recolectados en la secretaría de la escuela con verificación del formulario de matrícula de los 211 estudiantes matriculados en 2019 y complementados en el cuestionario respondido por 90 estudiantes elegidos aleatoriamente entre los matriculados. Los resultados de la investigación revelan que las características encontradas en los estudiantes de la escuela investigada son presentes y significativas en el grupo social extendido que utiliza esta modalidad como alternativa docente para completar el ciclo de educación básica. La encuesta también reveló que las características de los estudiantes coinciden con las del grupo negro de denominación étnica, lo que lleva a la conclusión de que EJA, en su forma planificada e implementada, tiene un destino determinado: brasileñas y mujeres brasileñas de los estratos más expropiados. de la sociedad, que históricamente coincide con negros, indígenas y algunos blancos económicamente desfavorecidos.

Palabras clave: EJA. Relaciones étnico-raciales. Amapá.

\section{INTRODUÇÃO}

As políticas de desenvolvimento regional precisam levar em consideração os cidadãos que vivem na região e trabalham gerando a riqueza, no sentido de desenvolver e aproveitar seus potenciais 
criativos e de distribuir a riqueza gerada em forma de melhoria de vida. Para que isso seja possível, tanto a elaboração das políticas quanto a distribuição com equidade precisam de conhecimento sobre os sujeitos que se relacionam entre si como indivíduos e como grupos no espaço regional.

No caso da Educação de Jovens e Adultos (EJA), fatores como: idade, evasão escolar, trabalho, família se entrelaçam exigindo uma atenção especial para os sujeitos que dela participam, pois, tais sujeitos têm história de vida significativa, estão inseridos de alguma forma no mundo do trabalho, têm uma identidade cultural e cumprem ativamente vários papéis sociais como pais, mães, esposos e eleitores.

Com referência à relevância e pertinência da pesquisa realizada, tem-se o fato de que a formação docente, de modo geral, pouco tem tratado sobre o modo como os educandos (re)constroem sua identidade e sua consciência e como suas inter-relações contribuem nesse processo. Nem tem havido contribuição significativa dessa formação para uma compreensão mais crítica da subjetividade na construção do conhecimento. Daí o interesse pelo estudo, especificamente para investigar o preconceito étnico-racial na EJA, tendo como foco de análise a percepção, tomada como base do processo cognitivo e da consciência (MARTINS, 2011).

Ao referir-se à EJA, Gomes (2005) destaca que se trata de processo que envolve política e práticas dirigidas aos educandos dessa modalidade de ensino e que se realiza fora e dentro da escola, lembrando também que tais sujeitos em aprendizagem "vivenciam múltiplas e diferentes experiências sociais e humanas" (GOMES, 2005, p. 87). Tais experiências vivenciadas individual e coletivamente são apreendidas e significadas de forma subjetiva, denotando o caráter especial da percepção, ou seja, de como as vivências/experiências são significadas e o que elas provocam enquanto consciência que atua no mundo.

Ainda, segundo Gomes (2005, p. 87-88), "mesmo que participem de processos socioeconômicos, políticos e educacionais semelhantes, esses sujeitos atribuem significados e sentidos diversos à vida, à sociedade e às práticas sociais das quais participam no seu cotidiano", concluindo que há uma variabilidade de formas de 
conceber, viver e ser 'jovem' e 'adulto' nas diferentes sociedades e culturas.

Percebe-se, então, que toda e qualquer experiência é significada de forma subjetiva ainda que seja vivenciada coletivamente. Essa significação é filtrada no estágio da percepção que, por sua vez, é condicionada pelas crenças e experiências já vividas do indivíduo. Tal situação põe em questão a importância e a necessidade do diálogo, como forma de entendimento e comunicação entre os sujeitos na construção de um projeto de interação, de vida coletiva e de compartilhamento, capaz de remover preconceitos.

É pertinente destacar que quando se fala em EJA, está-se referindo a um grupo social que não concluiu a educação básica na idade própria ${ }^{4}$. Nele incluem-se, os que foram excluídos do sistema de ensino ou não concluíram as etapas da educação básica na idade considerada regular, de 14 (quatorze) anos para o ensino fundamental e 17 (dezessete) anos para o ensino médio.

A pesquisa focaliza a EJA como recorte da Educação Básica onde encontra-se entrelaçada a questão do preconceito étnico-racial e do racismo. Nesse sentido, o desafio é perceber as linhas que produzem a tessitura dinâmica do preconceito e do racismo entre os educandos jovens e adultos. Assim, ao examinar tais questões, serão consideradas como fundamentais os sujeitos e os contextos que os envolve e os produz como seres de relações.

Nesse sentido, os estudos de Barcelos (2015) e de Soares (2011) trazem contribuições importantes para a construção de um perfil desse universo de educandos, cujas características remetem ao contingente populacional explorado e excluído do usufruto da riqueza que geram. Tais formas de exploração e de exclusão dão-se por meio do racismo e do preconceito em suas diversas manifestações.

\footnotetext{
${ }^{4}$ Constituição Federal. Art. 208. O dever do Estado com a educação será efetivado mediante a garantia de: I - Educação básica obrigatória e gratuita dos 4 (quatro) aos 17 (dezessete) anos de idade, assegurada inclusive sua oferta gratuita para todos os que a ela não tiveram acesso na idade própria (BRASIL, 1988). Redação dada pela Emenda Constitucional $n^{\circ} 59$, de 2009.
} 
De acordo com Gomes (2005, p. 89),

é a partir do alargamento da concepção e da prática de EJA, compreendendo-a na sua dinâmica conflitiva no contexto dos processos e construções históricas, sociais e culturais, que encontraremos espaço para uma reflexão profícua entre EJA e a questão racial.

Os educandos da EJA - Ensino médio são jovens e adultos, homens e mulheres, que pertencem a uma determinada classe social: a de trabalhadores e trabalhadoras que recebem as menores remunerações na divisão social do trabalho, pelas tarefas que realizam, muitas vezes sem qualquer amparo legal quanto a direitos trabalhistas e previdenciários. Esses discentes entrelaçam as relações de trabalhadores com os provimentos familiares, além de serem pais e mães. Devido à falta de políticas públicas, enfrentam necessidades básicas de moradia, transporte, assistência à saúde, trabalho gerador de renda, fatores que contribuem para estigmatizar ainda mais o público da EJA (CORRÊA, 2019).

Esses jovens foram expulsos do sistema educacional, ou tiveram negado o acesso a ele. Lutam para manterem-se no sistema escolar e avançar na escolaridade. Segundo Corrêa (2019) o ensino não os ajuda a construir uma visão crítica da sociedade onde vivem e participam, tampouco Ihes auxilia na capacitação técnica para qualificar sua atividade laboral.

Diante deste contexto, o presente artigo tem como objetivo discorrer sobre o perfil dos educandos do ensino médio na modalidade EJA em uma Escola Pública Estadual em Macapá, estado do Amapá, Brasil, verificando a composição étnica e a ocorrência de educandos classificados como negros, ou como pretos e pardos segundo o Instituto Brasileiro de Geografia e Estatística - IBGE (BRASIL, 2010). A inclusão da questão étnico-racial e a sua relação com o racismo e com o preconceito, no diálogo dentro da EJA, ajuda a compreender outras tessituras na complexidade que envolve os jovens e adultos negros, já situados no campo dos explorados economicamente e onde se encontram também brancos, e indígenas igualmente despojados. 
O estado do Amapá possui atualmente uma população cuja composição étnica é plural, originada, principalmente, de europeus portugueses, de indígenas brasileiros e de africanos de diversas nações trazidos na condição de escravizados. Tal formação do amazônida amapaense, em processo a partir do século XVI, refletiuse no censo do IBGE realizado em 2010, onde a maioria das pessoas residentes se autodeclarou parda (65,2\%). No mesmo censo, apurouse: de cor branca: 24,0\%; de cor preta, 8,7\%; indígenas, 1,1\% e amarelos, 1,0\% (BRASIL, 2010).

A presente pesquisa trata-se de uma pesquisa qualiquantitativa de cunho exploratório que utilizou da pesquisa bibliográfica, da análise documental e aplicação de questionário (MINAYO, 2001). Os dados foram coletados na secretaria da escola com verificação da ficha de matrícula dos 211 educandos matriculados em 2019 e complementados no questionário respondido por 90 educandos escolhidos aleatoriamente entre os matriculados. Os dados foram analisados tendo como fundamentação teórica a Análise Dialógica do Discurso, desenvolvida a partir do trabalho de Bakhtin (2003).

De início, no artigo será configurado o perfil dos educandos, considerando as características pesquisadas que levam à ideia tanto de grupo quanto de indivíduo, e em seguida se relacionará as características encontradas pela pesquisa com a configuração da EJA no Brasil. Na sequência, se verificará a proximidade de perfil entre o educando da EJA e o grupo definido sociologicamente como negro.

\section{DESENVOLVIMENTO}

Para o desenvolvimento do estudo, foi delimitado como campo de pesquisa uma escola estadual localizada na da cidade de Macapá, estado do Amapá. A escola foi criada no ano de 1995 para atender com ensino fundamental e supletivo. No decorrer dos anos a escola implantou o ensino médio e em 2019 ofereceu à comunidade: a) o ensino regular fundamental II do sexto ao nono ano; b) o equivalente ao ensino fundamental II na modalidade EJA, terceira e quarta etapas; c) o ensino médio nas modalidades Regular e EJA. A escola iniciou o período letivo em maio de 2019 com 1.505 
educandos matriculados nas diversas séries e etapas da educação básica.

As turmas do ensino fundamental regular funcionam nos turnos da manhã e da tarde e foram organizadas nos anos: sexto ano, 156 educandos; sétimo ano, 145 educandos; oitavo ano, 123 educandos e nono ano com 133 educandos. As turmas de ensino fundamental II na modalidade EJA foram organizadas em etapas sendo que 84 educandos se matricularam na terceira etapa e 79 educandos matricularam-se na quarta etapa.

Por sua vez, as turmas de ensino médio regular funcionam no segundo e no terceiro turnos tendo sido matriculados em 2019: no primeiro ano 255 educandos; no segundo ano 171 educandos e no terceiro ano 148 educandos. Finalmente, as turmas de ensino médio, na modalidade EJA, funcionam no terceiro turno com 88 educandos matriculados na primeira etapa e 123 educandos matriculados na segunda etapa, sendo 127 do gênero feminino e 84 do gênero masculino.

O levantamento de dados iniciou na secretaria da escola e ocorreu no mês de abril. Em seguida um questionário foi aplicado no período de dois a quatro de maio, durante a primeira semana do ano letivo, nos horários de aula, com todos os educandos informados que se tratava de coleta de dados e informações referentes a uma pesquisa sobre a percepção dos educandos da EJA sobre o racismo e o preconceito, sendo voluntária a participação e de caráter pessoal as respostas. Participaram educandos das seis turmas de EJA do ensino médio, sendo três de primeira etapa e três de segunda etapa. Os dados coletados foram organizados considerando os aspectos relacionados ao local de moradia, idade, situação civil, religião, gênero, orientação sexual, cor/etnia, naturalidade e ocupação dos educandos.

No ano de 2019, conforme levantamento realizado junto à Secretaria de Estado da Educação do Amapá, 27 estabelecimentos da rede estadual em Macapá ofereceram ensino médio na modalidade EJA, quase todos no período noturno, com exceção do Centro de Estudo Supletivo Paulo Melo, que organizou seis turmas em cada turno (manhã, tarde e noite), sendo três turmas de primeira etapa e três de segunda etapa e também das escolas estaduais Lucimar 
Amoras Del Castillo que ofereceu no turno da tarde uma turma de primeira etapa e uma de segunda etapa e da escola Professora Benigna Moreira de Souza que ofereceu uma turma de segunda etapa à tarde.

Dos bairros que fazem fronteira com o Novo Horizonte apenas no Jardim Felicidade se ofereceu em 2019 o ensino médio na modalidade EJA; a Escola Estadual Maria Neuza do Carmo ofereceu no período noturno três turmas sendo duas de primeira etapa e uma de segunda etapa.

Excetuando-se o Centro de Estudos Supletivos Paulo Melo, que é um estabelecimento destinado exclusivamente ao atendimento de jovens e adultos, as demais escolas oferecem a educação de jovens e adultos nos ambientes onde funcionam também o ensino regular fundamental ou médio.

No item do questionário referente ao local de moradia das pessoas matriculadas, verificou-se que a maioria reside no bairro Novo Horizonte, onde se localiza também a escola pesquisada, sendo esta a única escola no bairro que oferece ensino médio na modalidade EJA. A Tabela 1 relaciona os bairros de residência das pessoas matriculadas em 2019.

Tabela 1 - Bairro de residência das pessoas matriculadas no ensino médio, EJA, na escola pesquisa, em 2019.

\begin{tabular}{|c|c|c|c|c|c|c|c|c|c|c|c|}
\hline Item & $\begin{array}{l}\text { गే } \\
\text { o̊ }\end{array}$ & 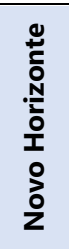 & 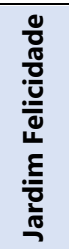 & 쁘 & 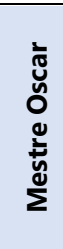 & 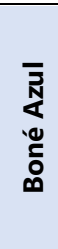 & 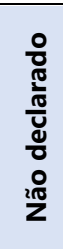 & 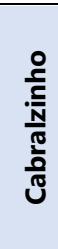 & 苞 & 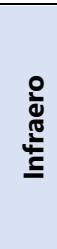 & $\begin{array}{l}0 \\
\stackrel{0}{0} \\
\text { N } \\
0 \\
\stackrel{0}{0} \\
\Sigma\end{array}$ \\
\hline $\begin{array}{l}\text { Quanti } \\
\text { dade }\end{array}$ & 211 & 151 & 27 & 14 & 6 & 5 & 4 & 1 & 1 & 1 & 1 \\
\hline$\%$ & 100 & 71,6 & 12,7 & 6,6 & 2,8 & 2,4 & 1,9 & 0,5 & 0,5 & 0,5 & 0,5 \\
\hline
\end{tabular}

Fonte: Os autores (2019).

O bairro Novo Horizonte é um bairro de periferia e localiza-se na zona norte da cidade de Macapá fazendo fronteira ao norte com a Área de Preservação Ambiental do Curiaú (APA do Curiaú), onde se 
encontra a comunidade quilombola do mesmo nome. À leste o bairro Novo Horizonte faz fronteira com o Lago do Pacoval e ao sul com o bairro Jardim Felicidade. Na fronteira oeste encontram-se os bairros do Ipê e o Conjunto Mestre Oscar. Mais de 90\% dos educandos moram no Novo Horizonte, Jardim Felicidade e Ipê.

Os bairros Boné Azul e Infraero não fazem fronteira com o Novo Horizonte, mas localizam-se na zona norte da cidade de Macapá. Por sua vez os bairros Cabralzinho e Marco Zero localizamse respectivamente nas zonas oeste e sul de Macapá a mais de 15 quilômetros da escola pesquisada.

Com relação à idade, verificou-se que as 211 pessoas matriculadas nasceram no período de 1960 (uma pessoa) a 2002 (quatro pessoas). A Tabela 2 retrata os educandos classificados por faixa etária, com uma concentração numérica nas faixas de idade a partir de 1990, que corresponde à idade máxima de 29 anos.

Tabela 2 - Faixa etária dos educandos matriculados no ensino médio, modalidade EJA, na escola pesquisada, em 2019.

\begin{tabular}{|c|c|c|c|c|c|c|c|c|c|c|c|}
\hline 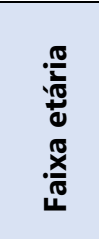 & $\begin{array}{l}\text { శึ } \\
\text { 。 }\end{array}$ & 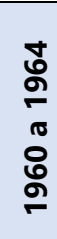 & 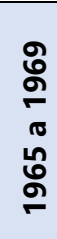 & 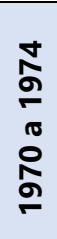 & 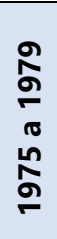 & 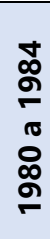 & 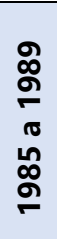 & 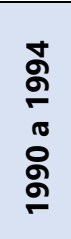 & 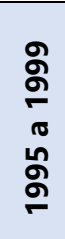 & 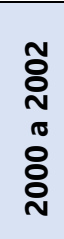 & 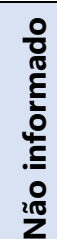 \\
\hline $\begin{array}{l}\text { Quanti } \\
\text { dade }\end{array}$ & 2111 & 6 & 2 & 5 & 8 & 17 & 12 & 33 & 86 & 38 & 4 \\
\hline$\%$ & 100 & 2,8 & 0,9 & 2,4 & 3,8 & 8,1 & 5,7 & 15,6 & 40,8 & 18,0 & 1,9 \\
\hline
\end{tabular}

Fonte: Os autores (2019).

Os dados levantados indicaram que $74,4 \%$ das pessoas matriculadas nasceu a partir da década de 1990 com significativa concentração no período de 1995 a 2002, representando 58,8\% dos educandos e correspondendo à faixa etária de 20 a 24 anos. Tais dados sugerem que a busca pela retomada dos estudos e conclusão do ensino médio ocorre cada vez mais cedo, ainda que alguns não continuem até a conclusão, levando-os a retornar à escola nos anos seguintes. Ao mesmo tempo os dados indicam que o sistema 
educacional regular continua produzindo as exclusões que alimentam a EJA.

Com relação à situação civil, foram consideradas duas condições: solteiro/a ou casado/a dentro das quais os educandos foram classificados. No primeiro caso os que não se consideraram em relações afetivas de convivência permanente como cônjuge; no segundo caso as pessoas em relações afetivas de casados ou como se casados fossem.

Do total de 90 entrevistados, 56 declararam-se solteiros e 32 declararam-se casados. Dois entrevistados, do gênero feminino não informaram a situação civil. Assim, entre os do gênero feminino, 34 declararam-se solteiras, 27 declararam-se casadas e duas não informaram a situação civil. Quanto aos do gênero masculino, 22 declaram-se solteiros e cinco declararam-se casados.

Dos 63 educandos do gênero feminino, 26 solteiras e 22 casadas declararam ter filhos. Dentre os 27 educandos do gênero masculino, três solteiros e quatro casados declararam ter filhos. A quantidade de educandos que declararam ter filhos correspondeu a $76,2 \%$ das mulheres e a $25,9 \%$ dos homens.

De acordo com a pesquisa, de modo geral ter filhos, na condição de menores de idade e dependentes, representou um estímulo para dar continuidade aos estudos, visando dar a eles futuramente melhores condições de vida. Ao mesmo tempo representou uma responsabilidade a mais no cotidiano dos educandos com relação a cuidados com a vida, acompanhamento e alimentação. Os educandos, para irem à escola, deixam os filhos menores sob cuidados do cônjuge, ou dos avós, ou de tios, ou de amigos, ou de outros irmãos, algumas vezes também menores. Algumas crianças e bebês, são levadas à escola principalmente pelas mães acompanhando-as durante o horário das aulas.

Com relação à religião, dos 90 participantes da pesquisa, 40\% declararam-se católicos, 34\% declararam-se evangélicos, ligados a várias denominações (evangélicos, testemunhas de Geová, Congregação Cristã do Brasil) e 10\% declararam não se identificar com nenhuma doutrina religiosa. Numericamente, 36 educandos declaram-se católicos; 34 declararam-se evangélicos; nove educandos declararam não ter religião; um educando declarou-se 
praticante da umbanda, um denominou-se apenas cristão; dois educandos declararam-se adepto de todas as religiões e sete educandos não informaram sua vinculação religiosa.

Entre os educandos que responderam o questionário, 78,9\% declararam identificar-se com o cristianismo e 1,1\% declarou identificar-se com a umbanda, religião de origem afro-brasileira, indicando que o cristianismo constitui uma forte característica identitária da maioria dos pesquisados.

Com relação ao gênero, conforme verificado no levantamento junto à secretaria da escola pesquisada e no questionário, o gênero feminino foi maioria entre os matriculados no ensino médio EJA em 2019. No levantamento pela ficha de matrícula, o gênero feminino representou $60,2 \%$ e o gênero masculino representou $39,8 \%$.

Com relação aos que responderam o questionário $70 \%$ foram do gênero feminino e $30 \%$ do gênero masculino (Tabela 3), mostrando o domínio do gênero feminino nas duas situações pesquisadas. No caso do levantamento pelo questionário foi verificada a relação entre gênero e cor/etnia dos educandos.

Tabela 3 - Gênero e cor/etnia dos educandos do ensino médio na modalidade EJA da escola pesquisada em 2019.

\begin{tabular}{c|c|c|c|c|c|c|c}
\hline Item & Total & Parda & Preta & Branca & Indígena & Amarela & $\begin{array}{c}\text { Não } \\
\text { informado }\end{array}$ \\
\hline Total & 90 & 70 & 10 & 6 & 1 & 1 & 2 \\
\hline Feminino & 63 & 49 & 7 & 4 & 1 & 1 & 1 \\
\hline Masculino & 27 & 21 & 3 & 2 & - & - & 1 \\
\hline
\end{tabular}

Fonte: Os autores (2019).

Considerando as três auto declarações mais recorrentes e utilizando a classificação do IBGE referente à cor/etnia, verificou-se que o gênero feminino representou $70 \%$ dos educandos de cor parda, $70 \%$ dos educandos de cor preta e $66,7 \%$ dos educandos de cor branca, predominando, portanto, o gênero feminino em cada cor/etnia.

$\mathrm{Na}$ questão da orientação sexual, dos 90 educandos que responderam o questionário, $82,2 \%$ declarou-se heterossexual; 2,2\% 
declarou-se homossexual; 4,5\% declarou-se bissexual; 1,1\% declarouse transexual e $10 \%$ não declarou a orientação sexual.

Com relação à cor/etnia dos 211 educandos matriculados no ensino médio-EJA, o formulário de matrícula solicitava a auto declaração de cor-etnia apresentando como possibilidades a classificação do IBGE (amarela, branca, indígena, parda, preta). A cor morena, que aparece na Tabela 4, assim como a cor negra, foram decorrentes de pesquisa em outros documentos na pasta dos educandos quando estes deixaram sem resposta o item referente à cor/etnia no formulário de matrícula. As declarações também foram atualizadas a partir da autodeclaração no questionário aplicado.

Tabela 4 - Cor/etnia dos educandos matriculados no ensino médio, modalidade EJA na escola pesquisada, em 2019.

\begin{tabular}{|c|c|c|c|c|c|c|c|c|c|}
\hline ㅎ & $\begin{array}{l}\overline{\text { गु }} \\
\text { 。ㅇ․ }\end{array}$ & $\begin{array}{l}\frac{0}{0} \\
\frac{0}{\frac{0}{0}} \\
\frac{\text { है }}{4}\end{array}$ & 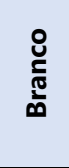 & 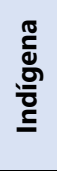 & 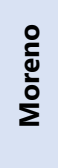 & 乙 & $\begin{array}{l}\text { 잉 } \\
\text { ż }\end{array}$ & $\frac{}{\frac{0}{0}}$ & $\begin{array}{l}\stackrel{0}{0} \\
\text { ڤั }\end{array}$ \\
\hline Quantidade & 211 & 1 & 24 & 1 & 10 & 2 & 4 & 146 & 23 \\
\hline Porcentagem & 100 & 0,5 & 11,4 & 0,5 & 4,7 & 0,9 & 1,9 & 69,2 & 10,9 \\
\hline
\end{tabular}

Fonte: Os autores (2019).

Quando as auto declarações de cor/etnia foram reorganizadas, juntando morena, negra, parda e preta na categoria negra, esta passou a representar $86,7 \%$ das pessoas matriculadas, seguida dos auto declarados de cor branca, com 11,4\%, dos não identificados com 0,9\%, dos indígenas com 0,5\% e dos amarelos, também com $0,5 \%$.

$\mathrm{Na}$ livre identificação outras cores/etnias foram declaradas, indo além daquelas determinadas pelo IBGE. O questionário respondido por 90 educandos apresentou um aumento das alternativas de autodeclaração com relação à cor/etnia ficando os educandos distribuídos quantitativamente da seguinte maneira: Parda, 59; Morena, 10; Preta, 8; Branca, 6; Negra, 2; Indígena, 1; Amarela, 1; Morena parda, 1; não identificada, 2.

Ainda com referência aos 90 educandos, para seguir a classificação do IBGE os auto declarados de cor/etnia morena e 
morena parda foram classificados como de cor/etnia parda e os auto declarados de cor/etnia negra foram acrescidos aos identificados como de cor/etnia preta, resultando nos seguintes percentuais: Parda, 77,8\%; Preta, 11,1\%; Branca, 6,7\%; Indígena, 1,1\%; Amarela, 1,1\%; não identificada, 2,2\%.

Quando reorganizados os registros de cor/etnia juntando parda, morena, morena parda, negra e preta, ou parda e preta, a categoria negra passou a representar $88,9 \%$ dos educandos que responderam a primeira parte do questionário.

Fazendo uma comparação de cor/etnia entre o total dos educandos matriculados e os que responderam o questionário verificou-se que no levantamento feito nas fichas de matrícula (211educandos), e no questionário (90 educandos) aparece em primeiro lugar a ocorrência cor/etnia parda, tanto na livre identificação quanto na classificação do IBGE, indicando que a maioria dos educandos se identifica como parda.

$\mathrm{Na}$ livre identificação apareceram, quantitativamente, as seguintes autodeclarações, em ordem decrescente: quanto ao levantamento dos 211 educandos: Parda, Branca, Preta, Morena; quanto ao levantamento dos 90 educandos: Parda, Morena, Preta, Branca. Na identificação usando os critérios do IBGE teve-se: quanto ao levantamento dos 211 educandos: Parda, Preta, Branca; quanto ao levantamento dos 90 educandos, também: Parda, Preta, Branca.

Essa comparação evidenciou, nas duas situações consideradas, a cor/etnia negra predominante entre os educandos do ensino médio na modalidade EJA matriculados na escola pesquisada em 2019.

Observando os educandos no ambiente escolar, verificou-se uma tendência de embranquecimento nas auto declarações de alguns. O pesquisador, utilizando como referência a cor da pele e a cabeleira, se não perguntasse tenderia a identificar visualmente vários educandos auto declarados de cor parda com a cor/etnia negra, assim como alguns autodeclarados brancos seriam identificados como de cor parda.

Observou-se também que alguns educandos auto identificados como de cor negra ou preta destacaram essa identidade principalmente nos arranjos na cabeleira e na participação em 
manifestações regionais de origem cultural negra como o marabaixo (dança típica da comunidade quilombola do Curiaú ou Cria-ú em Macapá-AP) e a capoeira, quando presentes essas manifestações nos eventos promovidos na escola.

Com referência à naturalidade dos educandos e de seus genitores, a pesquisa realizada nos formulários de matrícula revelou que não constam alguns dados como a filiação paterna do educando matriculado e a naturalidade dos seus genitores. Tais dados foram recolhidos por meio do questionário respondido por 90 educandos

Com relação à naturalidade, os 90 educandos do ensino médio EJA participantes da pesquisa declararam que nasceram em sete estados da federação brasileira sendo os estados do Amapá, do Pará e do Maranhão aqueles que tiveram mais registros com 54, 24 e cinco registros, respectivamente. Os demais estados declarados (Rio Grande do Sul, São Paulo, Ceará e Amazonas) tiveram, cada um, apenas um registro referente à naturalidade dos educandos. Três educandos não declararam a naturalidade. Percentualmente, o estado do Amapá representou 60\%, o estado do Pará $26,7 \%$ e o estado do Maranhão representou 5,6\%. Considerando o aspecto regional, $87,8 \%$ dos educandos nasceram na região norte e $6,7 \%$ nasceram na região nordeste.

Por sua vez os genitores dos educandos são naturais de dez estados brasileiros sendo três localizados na região Norte, cinco na região Nordeste e dois na região Centro-Oeste, conforme retratado na Tabela 5.

Tabela 5 - Naturalidade dos genitores dos educandos por região e por unidade da federação

\begin{tabular}{|c|c|c|c|c|c|c|c|c|c|c|c|}
\hline \multirow{2}{*}{ 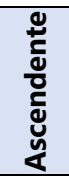 } & \multicolumn{3}{|c|}{ Norte } & \multicolumn{5}{|c|}{ Nordeste } & \multicolumn{2}{|c|}{$\begin{array}{l}\text { Centro } \\
\text { Oeste }\end{array}$} & \multirow{2}{*}{$\begin{array}{c}\text { Não } \\
\text { declarado }\end{array}$} \\
\hline & $A P$ & $P A$ & $A M$ & MA & PI & $C E$ & $R N$ & $B A$ & GO & MS & \\
\hline Mãe & 33 & 33 & 1 & 10 & 0 & 4 & 0 & 0 & 2 & 1 & 6 \\
\hline Pai & 28 & 32 & 0 & 13 & 1 & 2 & 1 & 1 & 0 & 0 & 12 \\
\hline
\end{tabular}

Fonte: Os autores (2019). 
Considerando a paternidade dos educandos por região, de acordo com as declarações, tem-se que $74,4 \%$ das mães e $66,7 \%$ dos pais são naturais da região Norte. Em seguida vem a região Nordeste com $15,6 \%$ das mães e $20 \%$ dos pais. Quanto aos casais de mesma naturalidade a pesquisa levantou 18 casais amapaenses, 15 casais paraenses, quatro casais maranhenses e um casal cearense.

Com relação à ocupação ou trabalho gerador de renda dos educandos foram consideradas, na data da pesquisa, uma das três situações: não possuir uma fonte de renda; ter uma relação de emprego; ou exercer uma atividade autônoma, sem vínculo de dependência direta com outra pessoa (Tabela 6).

Tabela 6 - Situação dos educandos com relação a atividade geradora de renda na data da pesquisa

\begin{tabular}{c|c|c|c|c|c}
\hline Item & Total & Autônomo & $\begin{array}{c}\text { Sem } \\
\text { renda }\end{array}$ & Assalariado & $\begin{array}{c}\text { Não } \\
\text { respondeu }\end{array}$ \\
\hline Total & 90 & 39 & 35 & 11 & 05 \\
\hline Feminino & 63 & 26 & 27 & 07 & 03 \\
\hline Masculino & 27 & 13 & 08 & 04 & 02 \\
\hline
\end{tabular}

Fonte: Os autores (2019).

Do total de educandos $43,3 \%$ declarou possuir uma atividade geradora de renda, 38,9\% declarou-se sem renda e 12,2\% declarou ter renda decorrente de trabalho assalariado. Considerando que na EJA os educandos de ensino médio têm idade a partir de 18 anos, notou-se um considerável percentual de indivíduos sem uma fonte de renda. Por outro lado, verificou-se uma precariedade do ponto de vista de proteção previdenciária para a maioria dos que desenvolvem atividades geradoras de renda, no caso os classificados como autônomos.

Considerando apenas os 63 educandos do gênero feminino, $42,8 \%$ declararam-se sem renda; 41,3 declararam-se autônomas; e $11,1 \%$ declararam-se assalariadas. Da parte dos educandos do gênero masculino, 48,2\% declararam-se autônomos; 29,6\% declararam-se sem renda e $14,8 \%$ declararam-se assalariados. Comparando os dois 
grupos verificou-se que as mulheres alcançaram resultados mais adversos representando, proporcionalmente, o grupo com mais indivíduos sem atividade geradora de renda, com menor acesso a emprego e com menor números de indivíduos engajado em atividade autônoma. A pesquisa mostrou também que quase a metade dos educandos do sexo masculino tiveram como fonte de renda o trabalho autônomo.

Dentre as atividades assalariadas foram declaradas as de operador de caixa, conferente em supermercado, merendeira (caixa escolar), auxiliar de serviços gerais, jovem aprendiz, operador de máquinas, auxiliar de escritório, garçom. Notou-se que alguns se relacionam com a administração pública por meio de empresas terceirizadas que prestam serviços aos entes da administração.

Dentre as atividades autônomas registraram-se: consertos de veículos automotores; diarista; vendedores de bijuterias, perfumes e roupas; pequeno comércio; decoração de festas; serviços gerais eventuais; pastor evangélico; manutenção de celular; venda de lanches; venda de comidas e bebidas; reformador de móveis; servente de pedreiro; manicure; prestador de serviços em Lan Houser; vendedor de cartelas de sorteios; prostituição.

Tanto no caso das atividades com vínculo subordinado (emprego) como no caso das atividades autônomas, de modo geral a renda mensal é inferior a dois salários mínimos e, no caso das atividades autônomas, estas não garantem segurança previdenciária, além de serem improvisações criativas para uma sobrevivência proba. Em casos de doença pessoal ou na família, os trabalhadores muitas vezes ficam sem qualquer fonte de renda, dependentes da solidariedade de parentes ou de pessoas da comunidade.

No questionário também foi perguntado sobre a motivação dos educandos para estarem frequentando e cursando o ensino médio EJA. Analisando as respostas verificou-se que há motivações que se entrelaçam em função dos objetivos que buscam na vida. Para uns concluir o ensino médio é chegar ao cume de sua caminhada escolar a partir do qual pretendem: procurar emprego; ter emprego melhor remunerado; ter condições de trabalho menos insalubres; ter um futuro melhor. 
Significa também, de modo geral, retomar e continuar os estudos que por diversas vicissitudes, nem tanto ocasionais, como filhos, reprovações e o próprio trabalho gerador de renda (CASTILHO, 2005, p. 3) os afastaram do avanço escolar regular.

Estudo do Instituto Nacional de Estudos e Pesquisas Educacionais Anísio Teixeira (INEP) referente ao ano de 2018, revelou um contingente de 3,5 milhões de educandos na EJA, sendo 59,5\% no ensino fundamental e 40,5\% no ensino médio (BRASIL, 2019). No estado do Amapá esses percentuais foram no mesmo ano, respectivamente, de $59,0 \%$ e $41,0 \%$. Ou seja, a diferença entre os níveis fundamental e médio fica em torno de $20 \%$, indicando que dois em cada 10 educandos que cursam o ensino fundamental na EJA não avançam imediatamente para o ensino médio nessa modalidade.

Para outros educandos da EJA a conclusão do ensino médio é meta intermediária para chegar à faculdade, colocada como condição para a obtenção de trabalho com melhor remuneração e também para a realização profissional e pessoal. Com relação ao aspecto da realização, sonham em tornar-se professor, assistente social, fisioterapeuta, policial e enfermeiro, o que indica uma forte sensibilidade social e o desejo de contribuir para resolver ou minorar os problemas sociais que vivenciam e percebem. Também se percebeu uma racionalidade na opção por cursos superiores mais acessíveis às suas possibilidades, inclusive financeiras, considerando que uma forma possível de concluir um curso superior é fazê-lo numa instituição privada, dada a competição e a limitação de vagas nas instituições públicas de ensino superior.

Configurando um perfil dos educandos do ensino médio na modalidade EJA que matricularam-se na escola pesquisada, pode-se dizer que são pais e mães, moradores de periferia, estudam em salas improvisadas, são desempregados, subempregados ou autônomos considerados de baixa renda, têm dificuldades de ordem econômica para concluir com sucesso e sem interrupções a educação básica na EJA, são negros, cristãos e heterossexuais.

Comparando o perfil dos educandos do ensino médio na modalidade EJA com outros dados e informações referentes à população brasileira, verifica-se várias coincidências ou semelhanças com o grupo social da nação brasileira mais expropriado econômica 
e socialmente. Nota-se também que outras desigualdades, como a de gênero, também são reproduzidas na Educação de jovens e Adultos, onde as mulheres, proporcionalmente, são a maioria sem renda e a minoria com alguma seguridade social (empregadas formalmente).

Segundo Gonçalves (2012, p. 39),

Na EJA o trabalho é uma questão muito presente: seja porque os alunos estão buscando manter seus empregos, seja porque estão procurando se qualificar para conseguirem um, seja porque acreditam que só com educação poderão conseguilo mais adiante. Mesmo os jovens que nunca tiveram essa experiência atribuem grande importância à escola para conseguirem uma profissão.

A conjuntura do início do século XXI não se mostra favorável aos educandos da EJA enquanto trabalhadores. O avanço tecnológico tem ocupado áreas onde os trabalhadores não especializados constituíam sua renda e o ensino não tem considerado essa realidade como tema e conteúdo para reflexão dos educandos. Os jovens e adultos não conseguem incorporar-se ao trabalho formal porque não há vagas, tendo eles de buscar sobreviver nas atividades informais enquanto são culpabilizados por tal situação (MARINHO; FREITAS, 2018).

Com relação à cor/etnia, a pesquisa revelou a prevalência dos negros, o que se alinha com as conclusões de pesquisas amplas realizadas nacionalmente mostrando que os sujeitos da EJA são de cor/etnia predominantemente negra. O estudo do INEP mostrou que no Brasil em 2018 os negros na EJA - os autodeclarados pardos e pretos - eram $39,9 \%$ e os autodeclarados brancos eram $16,0 \%$. Com referência ao estado do Amapá, os negros na EJA eram 52,9\% e os brancos 7,6\% (BRASIL, 2019).

Com relação ao gênero, o estudo do INEP identificou uma divisão, com pequena vantagem do gênero masculino. Tal equilíbrio verificou-se tanto na dimensão nacional (2\%), como também na região Norte (1,6\%) e no estado do Amapá (1,8\%), (BRASIL, 2019). Analisando os dados da pesquisa na escola pesquisada verificou-se 
no ensino médio EJA uma nítida maioria favorável ao gênero feminino. Outras pesquisas poderão responder se tal fenômeno é, por exemplo, um fato isolado, representa uma tendência ou ainda se é uma característica do ensino médio EJA.

Uma outra caraterística que entrelaça educandos da EJA, negros e camada mais expropriada da sociedade brasileira é o local de moradia. Estes sujeitos, que em muitos casos são os mesmos, habitam espaços de grande carência de serviços públicos, o que ocorre geralmente nos bairros periféricos. A pesquisa mostrou que os educandos são oriundos dos bairros periféricos de Macapá. Eles fazem parte, segundo o IBGE, do universo de mais de $64 \%$ dos brasileiros que possuem alguma carência em itens considerados básicos para a vida e dentre estes estão as condições de habitação e a infraestrutura física como vias trafegáveis, água tratada, esgotamento sanitário e iluminação pública, conforme se percebe nos bairros periféricos de Macapá no ano de 2019.

De modo geral duas características são delineadas de forma evidente na EJA. A primeira diz respeito à condição econômica dos educandos, onde aparecem de forma majoritária os desempregados, os subempregados, os sem renda, os autônomos prestadores de serviços com pouca exigência de conhecimentos tecnológicos mais avançados e complexos (COMIN, 2010, p. 379-382). A segunda característica é a cor/etnia negra, inclusive em regiões de maioria autodeclarada branca e onde há presença de pretos e de pardos. Ou seja, proporcionalmente os negros são maioria na EJA.

Essa realidade parece óbvia considerando que a EJA focou sua atenção para os jovens e adultos que não conseguiram concluir a etapa da educação básica na idade considerada regular, de 17 anos. Segundo Arretche (2015, p. 11), tal realidade decorre da desigualdade social no Brasil, que afeta as oportunidades educacionais. E os atingidos negativamente pelas desigualdades são majoritariamente os negros.

\section{CONCLUSÕES}

A pesquisa realizada para atender o objetivo geral de analisar a percepção dos educandos de ensino médio da EJA deu elementos 
empíricos a este estudo mostrando a reprodução das condições socioeconômicas e culturais que atingem os mais pobres, os negros, os indígenas e as mulheres. Tais condições repercutem na EJA onde também se observou ser esta modalidade de ensino destinada e esses grupos mais explorados.

A questão central da pesquisa, interrogando sobre o processo de reprodução do preconceito e do racismo na EJA, foi expressada no resultado, mostrando a imbricação dessas questões com os educandos que integram essa modalidade de ensino. A pesquisa também confirmou o pressuposto de que o preconceito e o racismo estão presentes e se reproduzem nas inter-relações dos educandos não somente no âmbito da escola, mas também na família, e na comunidade onde vivem. A pesquisa ainda contribuiu para acentuar a importância da temática étnico-racial no desenvolvimento regional, numa perspectiva de colocar como objetivo principal a construção de uma sociedade includente e valorizadora da vida.

O estudo demonstrou, a partir da percepção dos educandos do ensino médio, a existência de uma realidade que os mantém em grande desvantagem na estrutura social hierarquizada e que está sendo reforçada inclusive no aspecto educacional.

A pesquisa revelou que as características encontradas nos educandos da escola pesquisa que cursam o ensino médio na modalidade EJA estão presentes e significativas no grupo social ampliado que utiliza essa modalidade como alternativa de ensino para concluir o ciclo da educação básica.

A pesquisa ainda revelou que as características dos educandos coincidem com as do grupo etnicamente denominado negro, o que leva à conclusão de que a EJA, na forma planejada e implementada, tem uma destinação certa que são os brasileiros e as brasileiras das camadas mais expropriadas da sociedade, o que coincide historicamente com os negros, os indígenas e alguns brancos desprovidos economicamente.

\section{REFERÊNCIAS}

ARRETCHE, M. Trajetórias das desigualdades: como o Brasil mudou nos últimos cinquenta anos (Org.), São Paulo: Unesp, 2015. 
BARCELOS, V. H. L. Educação de Jovens e Adultos: currículo e práticas pedagógicas, 2. reimp. da 3. ed. Petrópolis: Vozes, v. 1, 2015.

BAKHTIN, M. Estética da criação verbal. Trad. Paulo Bezerra. 3. ed. São Paulo: Martins Fontes, 2003.

BRASIL. Constituição da República Federativa do Brasil. Brasília, DF: Senado Federal, 1988.

BRASIL. Instituto Brasileiro de Geografia e Estatística (IBGE). Síntese de indicadores sociais 2010: Uma análise das condições de vida da população brasileira, 2010. Disponível em: https://ww2.ibge.gov.br/home/presidencia /noticias/imprensa/ppts/0000000144.pdf. Acesso em: 20 set. 2017.

BRASIL. Instituto Nacional de Estudos e Pesquisas Educacionais Anísio Teixeira (INEP). Sinopse Estatística da Educação Básica 2018. Brasília: INEP, 2019. Disponível em:

http://portal.inep.gov.br/sinopses-estatisticas-da-educacao-basica.. Acesso em: 04 fev. 2019.

CASTILHO, A. P. L. A articulação entre o mundo do trabalho e a educação de jovens e adultos: reflexões sobre a incorporação dos saberes de alunos trabalhadores à prática pedagógica. In: 28 Reunião Anual da ANPEd, 16 a 19 out. 2005, Caxambu/MG. Disponível em: www.anped.org.br/reunioes-cientificas/nacional. Acesso em: 28 jan. 2019.

COMIN, A. A. Desenvolvimento econômico e desigualdades no Brasil: 1960-2010. In: ARRETCHE, Marta. Trajetórias das desigualdades: como o Brasil mudou nos últimos cinquenta anos (Org.), São Paulo: Unesp, 2010, p. 367-394.

CORRÊA, A. E. F. Racismo e preconceito na EJA: a percepção de educandos da Escola Rivanda Nazaré da Silva Guimarães, em Macapá, AP, 140f. 2019. Dissertação (Mestrado) - Universidade Federal do Amapá, Programa de Pós-Graduação em Desenvolvimento Regional. Macapá-AP, 2019.

GOMES, N. L. Educação de Jovens e Adultos e questão racial: algumas reflexões iniciais. In: SOARES, Leôncio; GIOVANETTI, M. A. 
G. de C.; GOMES, N. L. (Org.). Diálogos na educação de jovens e adultos. 1 reimp. Belo Horizonte: Autêntica, 2005, p. 87-104.

GONÇALVES, R. de C. Educação de jovens e adultos e o mundo do trabalho. In: LAFFIN, Maria H. L. F. (Org.). Educação de Jovens e adultos, diversidade e o mundo do trabalho. Rio Grande do Sul, ljuí: Unijuí, 2012, p. 28-61.

MARTINS, L. M. O desenvolvimento do psiquismo e a educação escolar: contribuições à luz da psicologia histórico-cultural e da pedagogia histórico-crítica. 2011, Tese (Livre Docência em Psicologia da Educação). Departamento de Psicologia, Faculdade de Ciências da Universidade Estadual Paulista, São Paulo (Bauru).

Disponível em: https://formacaodocente.

files.wordpress.com/2012/09/martins_ligia__o_desenvolvimento_do_psiquismo_e_a_educacao_escolar.pdf. Acesso em: 02 fev. 2018.

MARINHO, P.; FREITAS, M. Sociedades sem emprego: culpabilizar para flexibilizar (o sujeito). Revista Brasileira de Educação de Jovens e Adultos, v. 6, 2018, p. 41-52. Disponível em: http://www.revistas.uneb.br/index.php/educajovenseadultos/article/ view/5694/3635. Acesso em: 28 jul. 2019.

MINAYO. M. C. de S. (Org.). Pesquisa social: teoria, método e criatividade. 18. ed. Petrópolis: Vozes, 2001.

SOARES, L. (Org.). Educação de jovens e adultos: o que revelam as pesquisas. Belo Horizonte: Autêntica, 2011.

Submetido em: Julho/ 2021.

Aceito em: Agosto/ 2021. 